\title{
DISCUSIÓN SOBRE MONISMO NEUTRAL
}

\author{
MARGARITA M. VALDÉS \\ Universidad Naciona] \\ Autónoma de México
}

Las siguientes notas no pretenden ser más que una serie de reflexiones sugeridas por la lectura de la ponencia del profesor Trejo. La exposición que hace de las tesis generales del monismo neutral de Russell parece inobjetable, pero no así algunas de las conclusiones que saca a partir de ellas al final de su trabajo. Son éstas las que quisiera yo discutir.

Antes de pasar a considerar los puntos de vista de Trejo, me parece importante destacar, aunque sea muy brevemente, algunos de los objetivos que pretende alcanzar Russell al proponer las tesis del monismo neutral con el fin de hacer un balance posterior de la teoría.

En primer lugar, siguiendo un principio de economía ontológica, Russell intenta eliminar la dualidad psico-física elaborando para ello una teoría que le permita describir, o reconstruir, la realidad en sus aspectos físico y mental, a partir de un único elemento: las sensaciones aspectos o apariencias. Dichos elementos deberán ser de una indole tal que permitan a Russell cumplir con su cometido sin obligarlo a caer en una teoría monista que pudiera ser tachada de idealista o de materialista; esto es, deberán ser elementos "neutrales" en cuyos solos términos pueda ser descrito todo fenómeno físico o mental pero que ellos a su vez no sean de naturaleza ni material ni espiritual.

En segundo lugar, el empirismo que anima al Russell de este periodo vuelve a estar presente en esta teoría y lo lleva, ahora, a intentar una reducción más radical de todo lo existente a elementos dados en la experiencia, esto es, a considerar la realidad en último término como lo experimentable; de aquí su preocupación por negarle cualquier tipo de existencia al "yo" y al "objeto físico" entendidos éstos como entidades que trascienden la experiencia.

Por último, y relacionado con el punto anterior, hay también en Russell el intento persistente de adecuar su posición filosófica a las últimas teorías de la física y la psicología. Este es, tal vez, uno entre otros factores que pudiera servirnos para explicar por qué la pregunta "¿cuáles son los elementos últimos que constituyen la reali- 
dad?" cobra en ocasiones una ambigüedad peculiar. Por momentos resulta difícil de discernir si lo que está haciendo Russell al responder a dicha pregunta es elaborar una teoría metafísica claramente empirista o una teoría científica. ${ }^{1}$

Ahora bien, una vez colocados en esta perspectiva, quisiera retomar algunas de las cuestiones que plantea Trejo con el objeto de sugerir otras respuestas alternativas.

Si le concedemos al monismo neutral sus dos partes, esto es, el ser efectivamente una teoría monista y neutral, y sólo después nos preguntamos: "¿qué son estos elementos que constituyen la materia prima del mundo?", o, "¿qué es aquéllo que tienen en común el mundo mental y el físico?", nos veremos obligados a contestar, como lo hace Trejo, que dicha materia prima es algo "tan hipotético como el punto geométrico cuando éste se define como algo común a la recta y a la curva", y que lejos de ser dado en la experiencia inmediata resulta de una índole tan metafísica como la de las substancias tradicionales que se pretendía eliminar. Sin embargo, creo que dicha respuesta supone ya una interpretación o lectura parcial de las tesis de Russell; esto es, aceptar semejante respuesta implicaría desatender a algunas de las caractrizaciones de las sensaciones que en variados pasajes nos suministra el mismó Russell. A mi juicio el monismo neutral es efectivamente un intento de empirismo más radical, y si éste falla en sus propósitos no se deberá a que la teoría nos hable de las sensaciones como entidades hipotéticas o trascen. dentes a la experiencia, sino a otros problemas que veremos posteriormente. Antes, pues, de decidir si la teoría de Russell que aquí nos ocupa es efectivamente una teoría monista neutral, es necesario revisar otras de las caracterizaciones de las sensaciones que ofrece Russell con el fin de aclarar, en alguna medida, lo que entien. de Russell por sensaciones, aspectos o apariencias.

En The Analysis of Mind encontramos las siguientes afirmaciones: "In order, therefore, to arrive at what really is sensation in an occurrence $[\ldots]$ we have to pare away all that is due to habit or expectation or interpretatium"; "The essence of sensation $[\ldots]$ is its independence from past experience. It is a core in our actual experiences, never existing in isolation except possibly in very young infants"; "The stuff of the world [...] consists [...] of innumerable transient particulars such as occur in seeing, hearing, etc.".‘ Por

1 Sería importante plantearse aquí el problema de la distinción entre estos dos tipos de teorias, pero esto constituiría material suficiente para otro trabajo.

2 The Analysis of Mind, p. 140.

s. Op. cit., p. 144.

Op. cit., p. 143. 
último Russell nos suministra incluso algunos ejemplos concretos de lo que él llama sensaciones: "the sensation that we have when we see a patch of colour simply is that patch of colour [...] the patch of colour and our sensation in seeing it are identical". 5 Haciendo a un lado la dificultad que de hecho pueda existir para lograr una idea precisa de lo que sean las apariencias o sensaciones aisladas de todo elemento interpretativo u organización conceptual, parece que se desprende de las citas anteriores que las sensaciones a las que se refiere Russell no resultan demasiado diferentes de algunas de las experiencias que de ordinario designamos con el mismo nombre (por ejemplo cuando decimos "tengo una sensación de rugosidad"). Aún admitiendo que "sensación" en este sentido, tiene de ordinario un uso restringido de sensaciones táctiles o cinestésicas, no resulta absurdo pensar que dicho uso pudiera ampliarse de manera que nos permitiera referirnos a sensaciones conectadas con otros sentidos. Este uso técnico más amplio es el que Russell parece dar al término en cuestión. Así pues, una sensación podríamos decir, parafraseando a Russell, es una experiencia que consiste sólo en que ciertos datos sensoriales se hagan presentes a los sentidos. Es obvio que, como dice Ruseell, tales datos nunca o casi nunca se presentan aislados, esto es, desprovistos de toda estructuración, pero de esto no se sigue, como pretende Trejo, que las sensaciones sean entidades que no forman parte del mundo de nuestra experincia inmediata.

Podemos preguntarnos ahora, ¿por qué elige Russell precisamente las sensaciones como elemento último de la realidad? Russell encuentra que las sensaciones se hallan sometidas tanto a las leyes de la física como a las de la psicología; y si esto es así, cualquier fenómeno físico o mental podrá ser descrito en términos puramente de sensaciones y de distintos ordenamientos de las mismas. Esto es precisamente todo lo que una teoría monista neutral debe pretender.

Pero cabe plantearse algunas preguntas: ¿Es posible trazar una distinción clara entre esta posición monista supuestamente neutral y otra que pudiéramos llamar idealista? Decimos "supuestamente" porque parecería que si revisamos con cuidado la caracterización que ofrece Russell de los elementos últimos a partir de los cuales se construye la realidad, encontramos que éstos no son tan neutrales como Russell desearia. Dada la caracterización que él mismo ofrece de las sensaciones, parece inevitable considerar la existencia de órganos sensoriales o, como él mismo afirma más adelante, de un cuerpo viviente, ${ }^{\oplus}$ como condición necesaria para que se dé la sensa-

Op. cit., p. 142-143.

- Véase por ejemplo, Our Knowledge of the External World, p. 55 y The Analysis of Mind, pp. 143-144. 
ción. Pero, ¿cómo concebir un cuerpo viviente que experimenta sin admitir un sujeto empírico? Al tratar de aclarar Russell lo que entiende por sensación no le queda más remedio que acudir a un lenguaje de experiencia, y de ser esto así, está admitiendo implícitamente en el marco de la teoría un sujeto empírico que experimenta y al cual se le hacen presentes datos sensoriales a través de los sentidos.

En suma, para reconstruir la realidad Russell parte de una materia prima que, aunque él llama neutral, no podemos entender lo que ésta sea si no es referida a un sujeto que experimenta. Parece ser que la eliminación del dualismo físico-mental no pudiera hacerse más que a costa de adoptar un monismo que, fuese o materialista, o idealista, pero esta tercera vía tan aséptica y prometedora que vislumbra Russell no parece ser viable.

Ahora bien, dadas las tesis que sostiene Russell, ¿qué hacer para no caer en un idealismo similar al que sostuviera el obispo Berkeley, esto es, en una postura que (sin introducir la idea de una Divinidad) considerara existente sólo lo actualmente percibido, con todos los problemas que esto acarrea? La única salida estriba obviamente en admitir que exista algo que no sea necesariamente percibido, esto es, que no constituya propiamente una sensación. Russell pasa, pues, a sostener que hay aspectos o apariencias no experimentados. Dice asi: "If physics is true, there are, besides the particulars that we experience, others, probably equally (or almost equally) transient, which make up that part of the material world that does not come into the sort of contact with a living body that is required to turn it into a sensation." Tenemos pues un nuevo elemento: los sensibilia. Pero admitir la existencia de tales particulares sólo puede hacerse a costa de pagar un alto precio:

a) Por un lado, si Russell quiere ser coherente con su propósito de construir una teoría monista, tendrá que admitir: i) o bien, que se trata de un monismo en donde la realidad psico-física se explica a partir no de un solo elemento sino de dos: sensaciones y sensibilia, y que así como es necesario admitir sensibilia de lo material, habrá que admitir sensibilia de lo mental, cosa que además de acarrear otros problemas iría en contra de su idea de que la realidad es descriptible en términos sólo de sensaciones y distintos ordenamientos de las mismas: ii) o bien, que se sigue moviendo en la teoría monista anunciada y que los sensibilia lejos de ser otro tipo de elementos no son más que una subclase de las sensaciones posibles, no actualmente experimentadas. En este segundo caso tendrá que afrontar la dificultad de explicar lo que sea una "sensación" posible, esto

7 The Analysis of Mind, p. 143-144. 
es, que no forma parte de ninguna experiencia. ¿Qué es una apariencia que no aparece a nadie? Podría contestarse que los sensibilia tienen todas las características de las sensaciones excepto la de ser actualmente percibidas. Pero, además de las dificultades que conlleva semejante respuesta, entra en conflicto con la caractrización que el mismo Russell hace de las sensaciones; dado que ha eliminado la distinción que antes admitía entre sense-data y sensación (entendida ésta como la experiencia de tener un sense-data), las sensaciones de las que nos habla ahora parecen depender en cuanto a su existencia no sólo de los centros emisores de aspectos, si así queremos llamar a las cosas físicas, sino también de los centros receptores que en este caso serían los órganos sensoriales. Toda sensación tendría dos facetas por así decirlo: una que iría a integrarse en una estructura que pudiéramos llamar objetiva y otra que se integraría en una estructura que pudiéramos llamar biográfica. Por tanto parecería contradictorio afirmar al lado de esto que hay sensaciones no experimentadas, pues sería equivalente a admitir que hay sensaciones desprovistas de una de sus facetas constitutivas.

b) Por otro lado, la admisión de sensibilia, aunque necesaria tal vez para dar cuenta de la permanencia de los objetos físicos, podría pensarse que viene a menguar el rigor empirista de la teoría russelliana. Se abre la puerta a entidades que en un sentido no son experimentables en cuanto tales, pues al ser experimentadas dejarían de ser lo que son, esto es sensibilia, para convertirse en sensaciones.

Podemos ahora preguntarnos: ¿hasta qué punto cumple Russell con el programa del monismo neutral? Con respecto a lo "neutral" de los elementos que constituyen la materia prima del mundo, hemos visto ya las dificultades en las que Russell se ve envuelto. También resulta cuestionable que se trate de un monismo estricto. Para explicar el mundo de lo material no le basta a Russell con las sensaciones actualmente experimentadas, sino que hace intervenir a los sensibilia. Estos sin embargo, no parecen jugar ningún papel en la reconstrucción del mundo de lo mental. Hay, pues, al menos un tipo de particular, los sensibilia, que formarian parte de la realidad física pero no de la mental, y aquí el monismo se rompe. Por lo que toca a la explicación de lo mental, Russell también se ve obligado a admitir la existencia de otros nuevos parti. culares: las imágenes. Estas nos dice Russell, "no difieren intrín. secamente de las sensaciones", sin embargo, se hallan sometidas a leyes diferentes, están fuera del orden físico causal y se encuentran gobernadas sólo por la causalidad mnémica. ¿Qué es lo hace a Russell sostener que imágenes y sensaciones son intrínsecamente 
(cualitativamente) idénticas? Las razones no quedan claras en The Analysis of Mind, de manera que podríamos sospechar que se trata simplemente de una afirmación que, lejos de hacer más plausible la postura monista de Russell, se encuentra condicionada por ella.

Para terminar quisiera recoger algunas de mis concordancias y diferencias con las conclusiones de Trejo: $i$ ) Pienso, como él, que Russell no puede menos que admitir la existencia de ciertos elementos que forman parte de la realidad, aunque no así del mundo de nuestra experiencia inmediata: pero, a diferencia de Trejo, no considero que tales elementos sean las sensaciones (dada la caracterización que de ellas ofrece el mismo Russell en los pasajes de The Analysis of Mind antes considerados), sino aquellos otros elementos que no llegan a constituir propiamente una sensación: los sensibilia. Ahora bien, éstos no son admitidos arbitrariamente por Russell, sino que tiene que introducirlos para dar cuenta de ciertos hechos que su teoría pretende explicar: la permanencia de los objetos físicos, la regularidad de la experiencia. Podría pensarse que la admisión de estos elementos, no dados en la experiencia inmediata, viene a debilitar el rigor empirista russelliano, pero no admitirlos, la teoría se vería reducida a una descripción o explicación parcial de la realidad, esto es, explicaría algunos pero no todos los hechos que una teoría filosófica de este tipo debe, al menos, pretender explicar.

ii) Con respecto a la conclusión final de Trejo, en el sentido de que si hay tales elementos neutrales entonces son incognocibles, puesto así el condicional, pienso que es verdadero pero, a mi juicio, vacuamente verdadero, esto es, su verdad se sigue de la falsedad del antecedente. Si, en cambio, enunciamos de otra forma el condicional, diciendo, por ejemplo, "si hay sensaciones, entonces no son cognocibles", y aceptamos que el antecedente sea verdadero, entonces el enunciado completo sería verdadero, sólo en el caso de añadir al consecuente la frase "a la manera como lo son los objetos físicos". Russell mismo acepta esto cuando dice de la sensación: "it is not itself knowledge, but is supplies the data for our knowledge of the physical world". " Admitir que fuesen cognocibles seria equivalente a negarles el carácter, que Russell les da, de elementos últimos del conocimiento. Las sensaciones se introducen, en parte, para explicar el conocimiento de objetos físicos, de manera que si aceptáramos al lado de ésto que las sensaciones son también ellas mismas objetos de conocimiento, a la manera como lo son los objetos físicos, nos veríamos inevitablemente embarcados en una serie in.

8 The Analysis of Mind, p. 144. 
finita; tendríamos que explicar nuestro conocimiento de las sensaciones apelando a otro tipo de particulares (sensaciones de sensaciones) y así al infinito. Sin embargo, decir que no constituyen conocimiento, en el sentido en que lo afirma Russell, no es equivalente a sostener que no sean experimentables o, como dice Trejo, que no formen parte del mundo de nuestra experiencia inmediata.

iii) Por último, Trejo afirma que si las sensaciones no pueden darse fuera de una relación constructiva, entonces "no tendremos conocimiento alguno de lo que son en sí mismas" (el subrayado es mio). Esta afirmación parece implicar la aceptación de un principio general que dijera: $(x)$ si $x$ es un elemento que nunca se presenta aislado, entonces no podemos conocer lo que $x$ ses en sí mismo. La expresión "en sí mismo" pudiera interpretarse como "aislado de todo otro elemento", en cuyo caso el principio en cuestión resultaría tautológico y la afirmación de Trejo quedaría reducida a una mera trivialidad: dado que las sensaciones no pueden presentarse aisladamente, no pueden conocerse como algo aislado. Pero si lo que quiere decir Trejo es algo más fuerte, esto es, que por el hecho de presentarse las sansaciones estructuradas entre sí resultan incognocibles (o experimentables), entonces su afirmación sería verdadera sólo en el caso en que lográramos mostrar la validez de otro principio general: lo que no puede darse como un elemento aislado de otro elemento, resulta incognocible. Es obvio que podemos encontrar fácilmente casos que vengan a invalidar este principio: el rojo que veo en la camisa de Juan no algo aislable del resto de propiedades de la propia camisa, pero no por esto diré que el rojo no es cognocible, puesto que cognocible en este contexto no podría querer decir más que experimentable sensorial. mente. 